\title{
Masculinidad y violencia en el nuevo cine mexicano. Las películas de Luis Estrada*
}

Fecha de recepción: 04 de septiembre de 2015

Fecha de aprobación: 18 de enero de 2016

\section{Resumen}

En este artículo exploraremos la conformación de las masculinidades a través de las representaciones cinematográficas en América latina, específicamente en la obra del mexicano Luis Estrada, parte fundamental del llamado Nuevo cine mexicano en sus obras exhibidas entre 1999 y 2010. Aunque el universo de estudios de masculinidades es cada vez más amplio, las representaciones cinematográficas no han sido muy exploradas. Este artículo pretende hacer un análisis de las representaciones masculinas y su relación con las representaciones femeninas en el nuevo cine mexicano en un contexto de violencia desde una perspectiva crítica feminista.

Palabras clave: cine latinoamericano, masculinidades, crítica feminista, cine mexicano, representaciones masculinas.

\section{Claudia Elizabeth Puente \\ Vázquez}

Universidad Nacional

Autónoma de México

Doctoranda en estudios latinoamericanos, UNAM.

elibrugge@gmail.com

*Artículo de reflexión derivado de investigación en Doctorado de Estudios Latinoamericanos, CONACYT. 


\title{
la palabra
}

\section{Masculinity and violence in New Mexican Cinema: the Films of Luis Estrada}

\begin{abstract}
This article seeks to explore the formation of masculinities through their representations in Latin American cinema, specifically in the films of the Mexican director Luis Estrada, a fundamental artist in what has been called New Mexican Film; particularly in his works between 1999 and 2010. Even though the universe of masculinity studies is growing broader each day, its representation in cinema has not been widely explored. This article aims at examining the representation of masculinities and their relation to the representation of the feminine in New Mexican Film, amidst a context of violence, from a feminist critical perspective.
\end{abstract}

Palabras clave: Latin American film, masculinities, feminist criticism, Mexican film, masculine representations.

\section{Masculinité et violence dans le nouveau cinéma mexicain. Les films de Luis Estrada}

\section{Résumé}

Dans cet article on s'intéresse par la construction des masculinités dans les représentations cinématographiques en Amérique Latine, en particulier chez Luis Estrada qui fait partie du Nouveau cinéma mexicain (1990 et 2010). Bien que l'univers d'études de masculinités soit de plus en plus large, les représentations cinématographiques n'ont pas été très explorées. On fait une analyse des représentations masculines et leurs rapports avec les représentations féminines dans le nouveau cinéma mexicain dans un contexte de violence à partir d'une perspective critique féministe.

Mots clés: Cinéma latino-américain, masculinités, critique féministe, cinéma mexicain, représentations masculines. 


\section{Introducción}

El interés de este artículo es analizar desde la mirada crítica feminista la obra de un director mexicano contemporáneo, Luis Estrada. Esto, por la posibilidad que ofrece este enfoque de articular las relaciones del sujeto con la ideología, así como por la necesidad de reconceptualizar cómo se da la representación de las masculinidades en función del espacio relacional con lo femenino en ámbitos de representación en donde se hacen evidentes la violencia, el amor y la sexualidad. La crítica feminista apuesta por una comprensión más rigurosa y políticamente útil de los procesos de creación de imágenes en el cine, en la obra de un director que se ha considerado como uno de los más críticos al sistema político y económico actual, e incluso ha sido considerado como el director "incómodo" de México (Estrada, 2014).

El cine, como espectáculo masivo y globalizado, se torna una ventana de representaciones cuyos efectos performativos son tangibles, por lo que es necesario desarrollar herramientas críticas para abordar su análisis, en este caso, desde una crítica a los estereotipos construidos culturalmente a través del binomio de género. Lo anterior con la intención de desmontar las representaciones constantes del deber ser masculino dentro de contextos de violencias. En este artículo realizaremos un análisis, desde la crítica fílmica feminista, a dos cintas del director mexicano Luis Estrada, La ley de Herodes (1999) y El Infierno (2010), desde la forma en que se construyen las masculinidades en sus dos personajes protagónicos: Juan Vargas y el "Benny", respectivamente. Esto debido a que "Entre la variedad de personajes destaca siempre la acción del protagonista que se convierte en el agente causal principal y, por consiguiente, en el lugar privilegiado de la identificación del público. Su deseo marcará la trayectoria del relato, que se desarrollará en función de las dificultades que encuentra para conseguir la finalidad que desea" (Coll, 2000, p. 178). Lo que nos permitirá encontrar un punto focal para determinar los puntos de encuentro entre ficción y realidad y mostrar cómo el cine es un documento histórico con impacto social debido a su carácter global y performativo.

Este trabajo se dividirá, para su mejor desarrollo, en una exploración de la crítica fílmica feminista, el punto de enunciación de este artículo, para posteriormente hablar de los estudios de masculinidades y cómo éstos se han desarrollado a lo largo del tiempo, así como la forma en la que nos serviremos de sus herramientas para analizar las representaciones fílmicas. Continuaremos con el estudio de caso particular en el que hablaremos de la diégesis de ambas cintas y la masculinidad en sus protagonistas en relación con otros personajes.

II. Crítica feminista, cine y representaciones masculinas

Para comenzar el análisis de este artículo, comenzaremos por hacer explícita la teoría crítica feminista desde la que se analizará la obra de Luis Estrada, por lo que es menester hablar acerca del surgimiento de dicha teoría así como de sus principales herramientas de análisis. La crítica feminista es una crítica de la cultura que cuestiona cómo opera el aparato cinematográfico, cuya labor se opone al cierre totalizador de las afirmaciones sobre imaginarios y representaciones en las diferencias de género que se contienen en el espacio narrativo del cine clásico dominante (de Lauretis, 1984). Esta visión considera a la tecnología como un mediador que construye realidades como si éstas fueran autónomas, aunque mantienen una relación estrecha con la ideología dominante (Colaizzi, 2001), por lo que la intención de la crítica feminista radica en repensar los problemas de la significación genérica: la representación y los procesos subjetivos respecto a las masculinidades en un contexto histórico determinado, con miras a reformular una perspectiva de significado menos rígida, no desde una noción dada de masculinidad sino mediante un acercamiento desde los mecanismos de la tecnología social en la que ésta se construye. 
Es interés de este trabajo resaltar la relación del feminismo con el cine y la representación de las masculinidades a través de imágenes, representaciones, significados e ideologías; aunque también, hacer alusión a la posición social e histórica de las masculinidades, lo cual es una de las mayores contribuciones teóricas de los feminismos de segunda y tercera olas, dada su insistencia en las posiciones de clase y raza que afectan al género, en especial cuando adoptan la forma de representaciones dominantes $\mathrm{y}$ constituyen jerarquías sociales.

De acuerdo con Francesco Casetti (1994), la teoría fílmica feminista acoge un trabajo político, una práctica fílmica y una investigación académica. De esta manera, va más allá de la mera reflexión sobre el cine y se dirige a la actividad social, a los significados lingüísticos y semióticos y a la crítica ideológica. Esto implica también que la teoría fílmica feminista lleva consigo una práctica que tiene que ver con el análisis de la producción y la recepción de la realización cinematográfica que tiene impacto dentro del campo de los estudios culturales, la sociología, el psicoanálisis y los estudios sobre medios de comunicación. La tradición estudiada por Cassetti nos muestra 3 líneas de investigación fílmica feminista: la primera es de naturaleza metodológica, desde una mirada feminista que profundiza sobre instrumentos de análisis semiótico y nociones del psicoanálisis. La segunda línea de investigación trata de valorar el cine realizado por mujeres, sobre todo de los años 30 a los años 50 del siglo pasado. La tercera, de índole histórica, hace una relectura sistemática del cine clásico "patriarcal por excelencia" y expone a la luz los valores dominantes en el cine: la mujer como espectáculo, como objeto y como terreno de la sexualidad (Casetti, 1994). Es a partir de esta escuela de donde comenzarán a desarrollarse diversos estudios críticos feministas en torno al cine.

A partir de la segunda mitad del siglo XX se dará una producción rápida de los estudios feministas en torno al cine, a lo largo de distintas latitudes, de modo que el análisis textual del mainstream y trabajo en los archivos marcan esta primera producción crítica, fundada sobre la noción de género como diferencia sexual, que permite la articulación de un nuevo objeto teórico, el "cine de mujeres". La elaboración de dicho concepto es un hecho reivindicativo que tiene, como tal, sus límites y limitaciones y, como hemos observado en otro lugar (Colaizzi, 1997), tiene que ser entendido en su función estratégica: no pretende apuntar a una cualidad intrínseca al hecho de ser mujer que pueda marcar sustancial u ontológicamente la relación con la cultura de los sujetos históricos identificados con el género femenino, sino pretende focalizar la atención hacia los procesos históricos y culturales que han excluido sistemáticamente a las mujeres de la esfera de la producción cultural (Colaizzi, 2001, pág. viii)

La teoría crítica feminista en torno a la creación cinematográfica busca develar cómo a partir de las representaciones de género y el lugar asignado a la mujer dentro de las industrias cinematográficas se ha mantenido a éstas en un plano subalterno en la jerarquía social y de organización de dichas empresas; por lo que articula la identidad de género con otras categorías como la raza, la sexualidad, la clase, lo nacional, etcétera, en los espacios de creación y crítica cultural que tienen que ver con dispositivos y tecnologías de construcción género normativas. Por otro lado, se examina el universo femenino desde la composición de la audiencia y se plantean contribuciones relativas al papel de las mujeres en la creación de ciertos modos de ver las cosas y del peso específico de algunos motivos iconográficos en la participación femenina, al tiempo que se escribe una historia feminista al hacer visible la contribución de las mujeres a la industria fílmica.

La crítica feminista adopta el concepto de representación como parte de un constructo social e ideológico y considera que el aparato cinematográfico contribuye a la construcción de la diferencia sexogenérica. 
En general, las teóricas del cine critican el modelo de representación hegemónico al que se ha destinado a la mujer y proponen la realización de un cine diferente, con otro tipo de representaciones femeninas que rompan los modelos tradicionales. Las formas de analizar dichas representaciones, según Rivera (2013), van desde la situación mirada/poder a través de la objetivización sexual, como hace Colaizzi, y pasan por el placer del espectador masculino. De tal forma, podemos encontrar a una mujer ficción/representación/objeto y mujeres como seres históricos reales que no necesariamente son reflejados en pantalla.

En este tenor, las representaciones masculinas, aunque diversas, también mantienen ideas sujetas a un deber ser hegemónico. A pesar de encontrar personajes de diversas razas y clases sociales, los estereotipos de género se representan constantemente de la misma forma una y otra vez. Las fuentes de estudios de masculinidades en el cine son recientes aunque cada vez más abundantes, y se realizan desde diferentes puntos de vista: representaciones de masculinidades homosexuales, desde la épica y el cine clásico (Coll, 2000), desde puntos de vista descoloniales abordados desde miradas interseccionales (Castro Ricalde, 2002), entre otras. Todas ellas parten de origen de las teorías críticas feministas. Aunque exis- te una diversidad de abordajes, el cine con mayores estudios es el producido en Hollywood por su carácter masivo globalizante.

En el caso del cine mexicano, los estudios feministas han dado cuenta de los estereotipos femeninos, como el de María Félix (Castro Ricalde, 2002), que mantienen roles establecidos para la femineidad. Por su parte, las masculinidades en el cine latinoamericano, específicamente de la cinematografía comercial mexicana, han mostrado generalmente un machismo extremo y violento. El análisis de películas del cine de oro mexicano nos muestran con evidencia la formación de ideas que performan relaciones intergénero como el matrimonio y el noviazgo (Mercader Martínez, Matrimonio y mortaja del cine baja: estudio de su representación en el cine mexicano, 2004) y la formación de masculinidades tradicionales (Mercader Martínez, 2002) frente a las cuales los roles femeninos se sujetan a posiciones subalternas con características determinadas correspondientes a ideas de feminidad hegemónica; es decir, a mujeres sumisas y dependientes. En el cine mexicano contemporáneo resulta llamativo que los estudios de género que ponen atención en masculinidades y relaciones sexo amorosas hallan puesto sus ojos en los filmes de González Iñárritu, especialmente sobre la cinta Amores perros (Torres San Martín, 2008) (Prado, 2012).

\section{Masculinidades y repre- sentación}

En los filmes de Luis Estrada, podemos observar los imaginarios de patrones de comportamiento machistas. A través de la representación y narrativa fílmica podemos también observar la forma en que se representan los cuerpos, la sexualidad, la relación con lo femenino, los personajes que atraviesan los conflictos propios de la migración, del desarraigo, de la supervivencia en tiempos de la crisis económica, social y política que viven nuestros países. ¿Cómo el lenguaje del cine contribuye a representar ciertos imaginarios de las masculinidades en contextos históricos determinados?

Para responder a esta preguta, podemos afirmar con Scott (1990) que el género es "un elemento constitutivo de las relaciones sociales basados en la diferencia que distinguen los sexos [...] el género es una forma primaria de relaciones significantes de poder" (p. 29), por lo que podemos sostener que esas construcciones marcan sitios de enunciación para hombres y mujeres de maneras distintas, en épocas concretas. La interpretación de esta categoría como algo relacional es útil porque implica entender la idea de masculinidad, no como una categoría aislada sino en relación con la de feminidad y como parte de la construcción simbólica de los imaginarios 
sociales y culturales. Dichas construcciones simbólicas a través de representaciones sociales corresponden a relaciones de poder, por lo que es menester no sólo estudiar las características del género oprimido.

Si bien las posiciones feministas en la academia y el activismo, dieron cuenta de la situación de la mujer en un sistema de jerarquías de género, también comenzó a repensar al sujeto varón, y con ellos las ideas en torno a la masculinidad. La década de los ochenta se ubica como el momento histórico que marcó el desarrollo de los estudios de masculinidad. Maurice Godelier y Michael Kaufman son referentes reconocidos en este campo. Las reflexiones científicas en torno a los hombres, aún sin hacerse muy recurrentes y tomando caminos muy definidos, continuaron en Norteamérica y Europa, extendiéndose hasta América Latina con Matthew C. Gutmann, David D. Gilmore, Michael Kimmel, Robert Connell, Luis Bonino y Rafael Montesinos. Los principales temas desde los que se abordan son violencia, paternidad, identidad, salud-enfermedad, homosexualidad, entre otros.

A pesar de la cada vez mayor diversidad en los estudios de masculinidades, Connell (1997) apunta: "las principales corrientes de investigación acerca de las masculinidades han fallado en el intento de producir una ciencia coherente respecto a ella" (p. 31). Según Escutia (2015), existen tres líneas generales para estudiar las masculinidades: los profeministas, los mitopoéticos y los neomachistas. Los primeros abordan los estudios de las masculinidades desde un punto de vista crítico y realizan una crítica a sus privilegios; los segundos, se piensan de forma tradicional y apuestan por la continuidad de las masculinidades a partir de los cambios en los roles femeninos; los terceros, se encuentran en contra de cualquier cambio en la estructura jerárquica del binomio de género. De tal forma que, encontramos que los estudios de masculinidad no son homogéneos y se encuentran, en algunas ocasiones, en polos opuestos. Hay que partir de que la masculinidad es una categoría no coherente de la cual se pueda producir una ciencia generalizada, aunque sí es posible tener un conocimiento coherente acerca de los temas, las discusiones y debates surgidos a raíz de esos esfuerzos.

Cuando hablamos de masculinidad, la idea nos remite a un modelo histórico sociocultural de ser hombre que se construye sobre la base del sexo biológico. Aunque el sistema social busca asignar una sola identidad masculina a todos los hombres, de dominio y control, conocida como la masculinidad hegemónica, hay otros elementos externos e internos que inciden en la construcción de la misma y que permiten que puedan existir simultáneamente distintas identidades masculinas. El privilegio masculino no deja de ser una trampa y encuentra su contrapartida en la tensión permanente, a veces llevada al absurdo, de imponer a cada hombre el deber de afirmar en cualquier circunstancia su virilidad. Ésta, entendida como una capacidad reproductora, sexual y social, pero también como aptitud para el combate, y para el ejercicio de la violencia, que puede llegar a ser una pesada carga. Todo contribuye así a hacer del ideal imposible de la virilidad, el principio de una inmensa vulnerabilidad.

Es posible definir que la masculinidad es un constructo histórico cultural, de modo que se encuentra lejos de determinismos biológicos o la mirada etnocéntrica que tiende a la universalización de una forma particular de ser hombre, como si ésta fuese la única posible y verdadera. La realidad es que las concepciones, lo socialmente atribuido, las exigencias, los roles y las prácticas en torno a este concepto, varían según los tiempos y lugares. Las condicionantes que propician la dominación masculina, que se expresa de manera generalizada por la cultura patriarcal, descansa en un orden simbólico. Pierre Bourdieu plantea que la violencia simbólica a través de la cual se perpetúa dicha supremacía, se localiza en el habitus y se realiza a través de "un acto de cognición 
y de falso reconocimiento que está más allá de, o por debajo de, los controles de la conciencia y la voluntad" (Bourdieu citado en Lamas, 2000).

La masculinidad debe ser entendida como un sistema simbólico con múltiples posibilidades de significación (Connell, 1997), de tal forma que se presenta como un concepto complejo. La identidad masculina se construye bajo el criterio de lo que no es exclusivo de las mujeres, no se define por sí mismo, sino sólo en función de la otra. Ese deslinde, esa marcación de fronteras, se da en todos los campos de la práctica social (Badinter, 1993). Para Matthew Gutmann (2000) se establecen tres definiciones claves de masculinidad:

1) La masculinidad es por definición cualquier cosa que los hombres piensen o hagan.

2) Todo lo que los hombres piensen y hagan para ser hombres.

3) Algunos hombres, inherentemente o por adscripción, son considerados más hombres que otros hombres.

Así, es posible entender que la masculinidad es cualquier cosa que no sean las mujeres. A partir de ahí es imprescindible remitirse a la idea de que los mecanismos culturales y sociales empleados para demostrar que se es un "hombre de verdad" varían en función de la época histórica, la clase social o la etapa de la vida. Desde la antropología social, podemos comprender que "[...] la masculinidad no se expresa de manera universal, pues no se trata de un rasgo social constante, sino de manifestaciones propias de diferencias culturales coexistentes en un momento determinado de la historia, sin negar el predominio de formas de expresión de la propia masculinidad" (Montesinos, 2002, p. 75).

Así, las masculinidades han sido clasificadas por Connell (1997) según los roles que cada una adopta en la organización patriarcal, de la siguiente forma:

1) Masculinidad hegemónica: es la practicada por los varones heterosexuales que monopolizan el poder, el prestigio, y la autoridad legítima no sólo dentro de su grupo, sino también en la relación con las mujeres.

2) Masculinidad subordinada: hace referencia a formas de masculinidad divergentes de la posición de poder hegemónica de los varones. Se suele asociar a los homosexuales o a los "afeminados".

3) Masculinidad cómplice: se trata de las formas de masculinidad silenciosa, que no forma parte de la mayoría hegemónica pues no concuerda con algunas de sus prácticas y no siguen sus discursos y posiciones ante determinados temas, pero que disfruta de las ventajas del sistema patriarcal, y la sumisión de la mujer.

4) Masculinidad marginada: se suele relacionar con los grupos étnicos minoritarios, $\mathrm{y}$ frecuentemente marginados. Aquí entran los individuos con conductas delictivas o patologizados desde el discurso médico, situados como hombres en el sitio de lo abyecto.

Esta tipología de masculinidades será la que usaremos en el análisis de nuestros personajes más adelante.

Los estudios de la masculinidad más destacados de entre los protofeministas sostienen que los esquemas patriarcales no ayudan a comprender quiénes son los hombres, ya que marginan las identidades masculinas que no se ajustan a los valores y símbolos de su sistema. Éstos hacen la distinción entre lo masculino y patriarcal e insisten en que el patriarcado es "una construcción específica de un tipo de masculinidad heterosexista, homófoba, racista y machista". (Martín, 2007, p. 90).

Por su parte, Margarita Pisano (2004) nos dice que el patriarcado y la globalización mantienen una lógica de dominación a través de valores como la conquista, la lucha, el sometimiento por la fuerza que se ha modernizado en una masculinidad neoliberal y globalizada que controla, vigila y sanciona igual que siempre, 
aunque esta vez a través de un discurso retorcido, menos desentrañable y en aparente diálogo con la sociedad en su conjunto, donde invisibiliza una misoginia más profunda, escondida $\mathrm{y}$, por tanto, más devastadora que la del viejo sistema patriarcal.

Hablar de representación de las masculinidades en el cine latinoamericano, específicamente en el contexto mexicano entre 1990 y 2010, es mirar un cruce de diversos ejes: políticos, económicos, sociales y culturales, que determinan discursos y prácticas sobre lo que se entiende y simboliza como lo masculino. Las representaciones masculinas en el cine de Luis Estrada están atravesadas por imaginarios derivados de la cultura política y social occidental, de contextos que son globales, nacionales $\mathrm{y}$ continentales.

Nos interesa explorar desde la perspectiva de la crítica feminista del cine, las representaciones de la masculinidad en el cine latinoamericano; en específico, los filmes del cineasta mexicano Luis Estrada: La ley de Herodes y El infierno.

III. Masculinidades en el infierno, el cine de Luis Estrada

Los filmes de Luis Estrada son una crítica desde la sátira al sistema político mexicano. En $L a$ ley de Herodes (Estrada, 1999), el director ofrece su mirada sobre el tema de la corrupción en el sistema político mexicano. En $E l$ infierno (Estrada, 2010), aborda la violencia propiciada por el crimen organizado en el país. Ambas películas son controversiales y provocadoras y han desatado polémica por criticar símbolos sociales y políticos que eran intocables en la cinematografía comercial mexicana posrevolucionaria. En lo particular, y a pesar de la mirada crítica del director sobre dichos procesos sociales e históricos, nos interesa explorar cómo se representa la masculinidad en los personajes, dentro de un contexto situado, en el que imperan relaciones sociales determinadas por la violencia, la corrupción y el narcotráfico. Desde nuestro punto de vista, los personajes masculinos proyectan una serie de actitudes, valores y comportamientos que marcan imaginarios de género, lo que sostiene narrativas y estéticas específicas en respuesta a cierta dinámica que produce y reproduce imaginarios de una masculinidad específica.

Se seleccionaron estas dos películas porque responden al uso de personajes tipo que nos muestran, a través de las representaciones corporales y sus perfiles psicológicos, características de formas concretas de masculinidades en contextos de violencia y corrupción a partir de la idea de llegar a ser el "más fuerte". Esto a partir de cualidades físicas, aunque sobre todo de astucia para conseguir prestigio a través del arribo a posiciones de privilegio de un sistema corrompido. Estrada además utiliza al mismo actor como protagonista de ambas cintas, lo que nos permite observar la evolución de dos personajes con trayectorias similares en dos situaciones diferentes.

El cine construye sus modelos de género y expresa el consenso de la ideología dominante, "Una representación es ante todo una construcción lingüística dotada de cierta convencionalidad" (Casetti, 1994, p. 151). Es decir, el cine tiene un lenguaje específico caracterizado por sus representaciones y formas narrativas; las representaciones de género que hay en él se circunscriben a dicho lenguaje, que consta de imágenes, sonidos y en algunos casos, omisiones. Este lenguaje hace evidente la construcción de modelos sociales, ya que aunque el cine no es un espejo de la realidad, en él es posible detectar posiciones que se contraponen en el espacio social, "La realidad se falsifica, se sustituye al mantener lo primitivo, lo exótico, lo sexual como lo Otro [...]" (Castro Ricalde, 2002, p. 35). Además, debemos recordar que estas obras son medios de comunicar situaciones y estilos de vida. Para Krin Gabbard, "No hay duda que los hombres aprenden a ser hombres yendo al cine. Probablemente no existe otro lugar más significativo donde se formen nuestras nociones incuestionables de virilidad" 
(Gabbard, 2008). A lo largo de su historia, el cine nos ha mostrado a través de imágenes masculinas las características que la conforman: el vaquero, el héroe, el guerrero, etcétera.

La ley de Herodes y el Infierno se inscriben en un contexto que corresponde a una dinámica de profundos cambios sociales y económicos en Latinoamérica: desigualdad, desempleo y precarización del trabajo, empobrecimiento, recorte de derechos y decadencia democrática, revueltas populares, represión del Estado y colapso social; además de corrupción, militarización, intensificación de las dinámicas del crimen organizado y el narcotráfico. El contexto de la industria fílmica mexicana es la puesta en marcha de políticas de cine en gobiernos de crisis neoliberal, en medio de una supuesta abolición a la censura de temas políticos, en donde se otorga incentivos estatales, sobre todo de tipo fiscal, que se quedan en proyectos poco críticos, vinculados a grandes empresas productoras o televisoras, o permiten que la gran industria hollywoodense utilice el territorio mexicano como gran escenario a cambio de promoción turística.

La representación de las masculinidades y su relación con lo femenino están en función de roles en determinados contextos, como es el caso de México de finales del siglo XX y principios de siglo XXI. Los personajes masculinos que transitan los filmes de Estrada forman parte de un universo de cambios económicos, políticos y culturales, que son producto a la vez que inciden en la construcción de estereotipos: políticos, curas y narcos. Esto da la posibilidad de que sus juicios y acciones se conviertan en un medio de comunicación ideológico poderoso respecto a las masculinidades. En los filmes analizados se representa la dinámica cultural de las relaciones heteronormativas donde sobresalen las figuras y representaciones de las mujeres como esposas insatisfechas, putas resignadas y/o profesionistas fálicas; por otro lado, tenemos al estereotipo de la bruja: mujer mala y masculinizada, hundida en el mundo de la corrupción, inmoral y perversa, como ocurre en la Ley de Herodes con Doña Lupe, la matrona del prostíbulo del pueblo, mujer de edad avanzada, de origen mestizo y un arreglo personal descuidado, corrupta y la única capaz de hablar y negociar con los hombres de poder: el cura y los políticos. De este modo, las representaciones producen y reproducen identificaciones subjetivas con los personajes que establecen imaginarios y simbolismos sobre lo que se entiende debería ser o definirse como masculinidad, aun cuando no correspondan a modelos hegemónicos.

Para analizar la conformación de las masculinidades en las cintas elegidas, tomaremos como principal referente al protagonista de ambas cintas, el tránsito que éstos tienen desde una posición de vulnerabilidad para transformar su subjetividad y su yo (representación externa) hacia una masculinidad mucho más típica. Para eso, mostraremos cómo se relaciona con otros personajes masculinos, primero desde una posición subalterna, y con los personajes femeninos, que cierran un ciclo de violencias trasladadas. Para realizarlo comenzaremos con una breve descripción de la cinta; después, analizaremos la conformación del personaje principal en cada una de las películas. Esto a partir de la idea de Todorov que subdivide el análisis de una narración según la historia o argumento, que nos permite observar las lógicas en las que se mueven los personajes, y el discurso, que nos ayuda a comprender la forma en la que está dispuesto el relato (Barthes, 1977).

La ley de Herodes, masculinidades de chingas o jodes

En primer lugar, analizaremos la cinta La ley de Herodes (Estrada, 1999), una comedia negra en la que se denuncia el funcionamiento del sistema político mexicano. Esta película ha sido analizada como parte de una crítica al México post revolucionario, como un fracaso de la revolución mexicana y su ánimo nacionalista (Rangel, 2006) (Haas, 2007), aunque también se la ha señalado como 
una obra que refleja la época de oro del cine mexicano (Cyr, 2010). La trama se ubica en 1949 durante el sexenio del presidente Miguel Alemán, pero con claras referencias a momentos posteriores. En ella se cargan las tintas contra el PRI, partido de gobierno, pero también contra su oposición, el PAN y el PRD, así como contra la Iglesia, al ser parte de una misma casta dirigente. La película es una crítica a la burocracia, la corrupción y el funcionamiento de las instituciones del Estado al servicio de unos pocos privilegiados. El filme cuenta la historia de Juan Vargas, un politiquillo de tercera que es nombrado presidente municipal de San Pedro de los Saguaros, pueblo de miseria, sin carreteras, con construcciones de adobe semidestruidas, con pocos habitantes de mayoría indígena.

Juan Vargas arriba a la presidencia municipal con un golpe de suerte; es apenas un pobre diablo al que sus superiores le dan el puesto porque nadie está interesado en ocupar tan peligroso lugar. El presidente municipal que lo antecedió fue linchado por los indígenas del lugar. Él cree que su función es traer: "la paz, el progreso, la modernidad y la justicia social", y se propone trabajar realmente por ello; al poco tiempo se da cuenta que no puede hacer nada contra la corrupción de los principales poderes del pueblo: la iglesia y el burdel. La cúpula de su partido pronto lo desilusionará y le dirá que debe gobernar a punta de pistola con la constitución en la mano.

Juan Vargas regresa a San Pedro y comienza a "ejercer la ley" a través del poder y la violencia. Se transforma en un tirano más del gobierno corrupto. Su labor es sacar el mayor beneficio posible de la situación. Lejos de ser castigado, es protegido y llega a ser diputado en el Congreso de la Unión. La iglesia también está implicada, negocia y saca beneficio del mismo modelo de corrupción. La película también permite observar la otra cara del sistema de corrupción generalizado, la cara de los pobres sobre los que se sustentan los privilegios de las autoridades. En el caso particular del pueblo de San Pedro de los Saguaros, nos encontramos con que la mayoría de la población, de origen indígena, no habla español porque no hay escuelas y viven en una situación de extrema exclusión social. Se trata de una población sobre la que se construyen discursos de modernización y progreso, los que justifican infraestructuras y planes de desarrollo, que se tornan posibilidades de negocio. Una población en realidad relegada y marginada por las autoridades del Estado, que sólo se relacionan con ellos en términos de ejercicio del poder y de obtención de recursos.

En esta cinta podemos observar cómo Juan Vargas, personificado por el actor Damián Alcazar, un hombre de edad media, de baja estatura, de piel morena y rasgos fuertes, va a encarnar a una masculinidad cómplice, según las clasificaciones de Conell mencionadas anteriormente. Esto implica a un sujeto que aunque no cumple con las formas de una masculinidad hegemónica, se encuentra en una posición de privilegio respecto a las mujeres con las que se relaciona; es decir, disfruta de las ventajas del sistema patriarcal. Este tipo de masculinidad se encuentra supeditada a la masculinidad hegemónica encarnada en los políticos más encumbrados dentro de su partido y tiene prebendas frente a las masculinidades marginadas, que en este caso son encarnados por hombres de rasgos étnicos, con lengua indígena.

La masculinidad de Vargas no va a ser constante a lo largo de la cinta, que nos enfrenta a una temporalidad dilatada en la que el personaje de "El Gringo" detonará la transformación de Vargas hacia una masculinidad hegemónica, esto es, hacia una actitud más violenta y que encaja de mejor manera en el micro sistema de corrupción dentro del pueblo que gobierna, así como en el macro sistema de corrupción en el que se mueve el partido político nacional al que pertenece. Hacia el final de la película, encontramos a un personaje principal convertido hacia prácticas de corrupción 
y violencia contra mujeres y hombres subalternos; su masculinidad ha adoptado rasgos de las masculinidades hegemónicas dentro de un sistema patriarcal que reserva las posiciones de privilegio a unos cuantos.

El tránsito de la masculinidad de Vargas va de la mano con la escalada de actitudes agresivas y la apertura a prácticas ilegales y de despojo, así como de enriquecimiento ilícito. El lema de la película, "O te chingas o te jodes" hace alusión a un comportamiento profundamente machista, ya que utiliza dos verbos que tienen que ver con el acto sexual; es decir, apuntan al uso sexual de un hombre sobre otro. La competencia entre masculinidades es otra de las constantes que podemos observar: por los espacios de poder, por la pareja, por recursos producto de la corrupción.

En cuanto a la relación de la masculinidad del protagonista con los personajes femeninos, podemos observar cómo también se modifica a lo largo de la cinta. Mientras al principio Juan Vargas aparece como un esposo condescendiente e influenciable, conforme avanza la trama y se constituye como una figura de poder, que es lo que ella buscaba, Vargas comenzará a relacionarse con las mujeres en general y con su esposa en particular desde una posición de privilegio. Las mujeres comenzarán a ser objetos sexuales a disposición de Vargas por tratarse del presidente municipal. Es posible observar cómo las construcciones de género atraviesan otros factores como raza, clase y edad, ya que las mujeres explotadas sexualmente en el burdel del pueblo son jóvenes con rasgos étnicos, mientras su proxeneta es una mujer de edad avanzada con rasgos masculinizados, quien tiene tratos con las autoridades civiles y eclesiales y forma parte del microsistema de corrupción.

Otros personajes masculinos son retratados a partir de una contraparte femenina. Tal es el caso del candidato de la oposición, el médico del pueblo que busca cerrar el burdel, mientras su esposa es ninfómana. De tal forma, podemos afirmar que Estrada retrata extremos de feminidad y masculinidad en donde es posible observar las jerarquías de género que se establecen socialmente. El cine, en este sentido, es el medio ideal para representar de qué manera lo personal deviene en una categoría expansiva. Aunque se trata de una obra retrospectiva, los estereotipos formados a lo largo del periodo posrevolucionario del siglo XX en México asistieron a la conformación de un profundo machismo que mantiene en un lugar subalterno a las mujeres y a los otros feminizados, los indios del pueblo que esperan pacientes el momento de la venganza que no siempre llega.

El tránsito de la masculinidad de La ley de Herodes se puede captar incluso en la posición de la cámara. La cámara gira siempre en un plano secuencia que no se detiene. El poder de la mirada es masculino. Juan Vargas demuestra su hombría a través de su virilidad. La cámara nunca frena, como tampoco él. Vargas es "tan potente sexualmente" que puede estar con todas las prostitutas del burdel al mismo tiempo y satisfacerlas.

El infierno, de migrante a sicario

En la película El infierno (2010), se narra la historia desafortunada de Benjamín García, "El Benny", quien es un migrante ilegal deportado de los Estados Unidos. Al llegar a la frontera, el policía norteamericano le quita las esposas y le dice Welcome to Mexico, don't come back. Enseguida comienza su recorrido de regreso a través de la ventanilla del autobús: un panorama de pobreza y desolación. En el camino, "El Benny" es asaltado dos veces, la primera por un ladrón convencional, la segunda es despojado por soldados. En este viaje, el protagonista es privado de sus bienes, de sus ropas y prácticamente, de su oportunidad de ganar un sustento, de su condición humana.

Al regresar a su pueblo, "E1 Benny" comienza "su descenso al infierno". Su pueblo está prácticamente desolado, desmantelado y solitario. Justo al llegar, Benjamín se topa con 
una balacera, de la que resulta un hombre muerto, y en donde se le informa que se encuentran en guerra. Posteriormente, vemos al protagonista en la vulcanizadora de su tío, Rogaciano García; un sitio a punto de la quiebra. Don Rogaciano le explica a Benjamín la situación del país, y en especial de San Miguel Arcángel: "Crisis, desempleo, violencia... Casi, casi como una guerra civil. Nos cayó la maldición a todos. En este pueblo te matan nomás por cualquier cosa". Este pueblo, el infierno, San Miguel Arcángel, o bien el norte de México, son mostrados como espacios sin ley. Un fenómeno producido por el narcotráfico y la corrupción, factores de expresión de la crisis postindustrial del capitalismo y la globalización. Es en ese infierno en el que "El Benny", se encuentra a su amigo "Cochiloco", quien lo llevará con "los Reyes". "Los Reyes" son el cartel dominante en San Miguel Arcángel. Benjamín García se enrola con ellos empujado por la necesidad. El patrón lo recibe en su despacho y le explica el trabajo, advirtiéndole no consumir lo que se trafica, advertencia que el protagonista va a desoír.

A lo largo de la cinta, en un símil con Vargas de La ley de Herodes, "El Benny" transitará de una masculinidad marginada, del migrante deportado, a una masculinidad cómplice en el sentido de Connell: su masculinidad se encontrará constantemente subordinada a la de sus jefes, "Los Reyes", que gozan de poder político y poseen el monopolio de la violencia soberana e ilícita. Su masculinidad será retada por la figura de su sobrino, mientras que las relaciones con otros personajes masculinos se llevan a cabo a partir de la violencia cómplice o infligida. Hacia el final de la película, la venganza es el móvil para enfrentar a la principal figura masculina de poder, aunque sólo a través del asesinato, la forma retratada en la hiperviolencia de la cinta.

Los personajes masculinos de su familia van a encarnar masculinidades hegemónicas, de carácter fuerte, sin el miedo ni la subordinación que caracterizarán al personaje protagonista. Por otra parte, "El Cochiloco" es un personaje que mostrará las diversas facetas que puede adoptar una masculinidad en diferentes espacios: de matón a padre de familia. Los personajes femeninos también mantendrán un símil con las mujeres representadas en La ley de Herodes: objetos sexuales dentro de espacios de prostitución o esposas que retratarán a una incipiente clase alta de pueblo. En ambos casos es posible observar los factores de clase en las formas femíneas, que retratan a algunas como mujeres hipersexuales, las de clase baja, y a las de clase media como burguesas hipócritas.
En El Infierno, la forma de abandonar la masculinidad marginada es a través de la violencia que incrusta al protagonista en un sistema de necroempoderamiento (Valencia, 2012); el desprecio de la vida es requisito para escalar en la jerarquía masculina en un horizonte desolador.

\section{Conclusiones}

Luis Estrada realiza un par de obras desde la sátira, comedias negras que sirven para mostrar de forma irónica la realidad política histórica de corrupción y el contexto actual de violencia y crimen organizado. Aunque no podemos afirmar que el cineasta también busque plasmar de forma sarcástica las relaciones de género, podemos observar que las películas están plagadas de chistes relativos a la hipersexualidad masculina que responde a los estereotipos de machismo más extremo en el país. En ellos, el homoerotismo se muestra de formas tradicionales, entre la sorna y la violencia. Las relaciones con las mujeres son de dominación, se trata en muchos casos de humanos abyectos. Todas estas formas de presentar el género corresponden a un orden social sostenido a partir de la violencia y la corrupción generadas a lo largo de procesos históricos, sobre los que el director de ambos filmes toma la decisión de reír para no llorar. El capitalismo gore (Valencia, 2012), puede resultar más aterrador que su contraparte ficcional. 


\section{Referencias}

Amador, C. P. (1996). El cine como documento social: una propuesta de análisis. Revista Ayer, 24, 113-145.

Badinter, E. (1993). XY: La identidad masculina. Madrid: Alianza editorial.

Barthes, R. (1977). Introducción al análisis estructural de los relatos. En: S. Nicolini (comp.). El análisis estructural. Buenos Aires: Tiempo contemporáneo.

Casetti, F. (1994). Teorías del cine 1945-1990. Madrid: Cátedra.

Castro Ricalde, M. (2002). Feminismos y teoría cinematográfica. Escritos. Revista del Centro de ciencias del lenguaje, 25, 23-48.

Colaizzi, G. (2001). El acto cinematográfico: género y texto fílmico. Lectora, 7, 5-13.

Coll, M. (2000). Las masculinidades en el cine clásico: la figura de la redención. En: M. Segarra y Á. Carabi. Nuevas masculinidades (pp. 153-177). Barcelona: Icaria.

Connell, R. (1997). La organización social de la masculinidad. En: T. Valdés y J. Olavarría. Masculinidad/ es. Poder y crisis. Chile: Ediciones de las mujeres/FLACSO.

Cyr, I. (2010). La herencia de la época de oro en el cine mexicano de los años noventa: La ley de Herodes y danzón. Montreal: Diss. Master Études hispaniques.

De Lauretis, T. (1984). Alicia ya no. Feminismo, semiótica, cine. Barcelona: Cátedra.

Escutia Díaz, S. (2015). El sujeto masculino. La construcción de su subjetividad genérica. En: H. C. (coord.). ¿Cuerpos recibidos o reconstruidos? (pp. 111-129). México: CIALC/UNAM.

Estrada, L. (Dirección). (1999). La ley de Heródes [Película].

Estrada, L. (Dirección). (2010). El infierno [Película].

Estrada, L. (2014, 7 de octubre de). Luis Estrada, el cineasta 'incómodo’ de México. (E. informador, Entrevistador).

Gabbard, K. (2008). Hombres de película. En: Á. Carabí y J. Armengol. La masculinidad a debate. Barcelona: Icaria.

Gutmann, M. (2000). Ser hombre de verdad en la Ciudad de México. Ni macho ni mandilón. México: COLMEX.

Haas, R.M. (2007). El cine contemporáneo mexicano (1999-2002): la destrucción y reafirmación de la identidad nacionalista en Lay ley de Herodes (1999), Amores perros (2000), y El crimen del padre Amaro (2002). Tesis doctoral. University of Otago, Nueva Zelanda.

Lamas, M. (2000). Violencia simbólica, mujeres y prostitución. En: H. Tejera. Antropología Política: Enfoques Contemporáneos (pp. 391-403). México: Plaza y Valdés/INAH.

Martín, S. (2007). Los estudios de la masculinidad. En: M. Torras. Cuerpo e identidad (pp. 89-112). Barcelona: UAB. 
Mercader Martínez, Y. (2002). La representación masculina en el cine mexicano. Anuario 2001 UAM Xochimilco, 291-299.

Mercader Martínez, Y. (2004). Matrimonio y mortaja del cine baja: estudio de su representación en el cine mexicano. Anuario de investigación 2003 UAM Xochimilco, 651-671.

Montesinos, R. (2002). Las rutas de la masculinidad. Barcelona: Gedisa.

Pisano, M. (2004). El triunfo de la masculinidad. México: Fem-e-libros.

Prado, I. M. (2012). El sublime neoliberal: Amor y temporalidad en el cine mexicano del capitalismo tardío. Arizona Journal of Hispanic Cultural Studies, 16, 293-310.

Rangel, L.C. (2006). La ley de Herodes (1999) Vs. Río escondido (1947): la desmitificación del triunfo de la revolución mexicana. Divergencias. Revista de estudios lingüísticos y literarios, 4, 61-68.

Rivera Ramírez, E. (2013). La reivindicación de la mujer en el cine: nodos entre el feminismo y los estudios cinematográficos. Revista Cuadrivio. Recuperado de http://cuadrivio.net/artes/la-reivindicacionde-la-mujer-en-el-cine-nodos-entre-el-feminismo-y-los-estudios-cinematograficos/

Scott, J. (1990). El género, una categoría útil para el análisis histórico. En: J.S. Amelang y M. Nash. (eds.). Historia y género: las mujeres en la Europa moderna y contemporánea (pp. 23-56). Valencia: Alfons el Magnanim.

Torres San Martín, P. (2008). La recepción del cine mexicano y las construcciones de género: ¿formación de una audiencia nacional? La ventana. Revista de estudios de género, 27, 58-103. 